\title{
Multiple amylase loci in Asellus (Crustacea: Isopoda): Genetics and linkage
}

\author{
G. S. Oxford
}

Department of Biology, University of York, York YO1 5DD, U.K.

Breeding studies, and subsequent analysis by polyacrylamide gel electrophoresis, indicate six amylase loci in Asellus aquaticus, five of which are polymorphic. Three loci investigated in detail (Amy $3, A m y$ and $A m y ~ 5)$ are very closely linked. Null alleles are present at each of these loci and, at $A m y$, reach fixation in many populations. In contrast to the variability in $A$. aquaticus, $A$. meridianus amylases are invariant in all populations studied.

\section{INTRODUCTION}

In 1977, Christensen reported a case of apparent habitat selection by different amylase genotypes of the water hoglouse, Asellus aquaticus (L.). Collections were made from a natural pond, the bottom of which was covered with rotting leaves; predominantly of beech at one end, and of willow at the other. Samples taken from the two ends showed significant differences in allele frequencies at the amylase locus. Animals collected from this pond, when offered a choice of beech or willow leaves in an experimental tank, migrated so as to give allele frequency differences between substrates similar to that found in the wild. These experiments have been repeated several times with the beech and willow choice (Christensen, 1977) and with combinations of these and Carex and Elodea (Christensen, personal communication). In all cases, some habitat selection was found.

The observation of apparent habitat selection by different genotypes raises a number of interesting questions. For example, by what mechanism(s) do genotypes choose particular types of leaves? Is the choice an adaptive one, i.e., is the fitness of a genotype on its chosen leaf higher than on other leaf types? Different species of leaves are likely to be colonised by different fungal species, an important source of food for Asellus (Rossi and Vitagliano-Tadini, 1978). Is there an association between amylase genotype and the ability to metabolise different fungi? A more general question is whether environmental heterogeneity per se, irres- pective of habitat choice, leads to an adaptive maintenance of the amylase polymorphism in this species.

Before any of these questions can be investigated experimentally, the genetic nature of amylase variation must be established. Lomholt and Christensen (1970) obtained breeding data which indicated that the three genotypes they recognised, designated $A_{1} A_{1}, A_{1} A_{2}$ and $A_{2} A_{2}$, were controlled by two co-dominant alleles at one locus. However, hints that the situation might not be as simple as this came from observations of animals carrying neither allele (Christensen, personal communication) and of "shadow" bands migrating more slowly than the $A_{1} / A_{2}$ system (Lomholt and Christensen, 1970; Robson, 1973).

In this paper I present breeding data for Asellus aquaticus which do indeed demonstrate a much more complicated situation with regard to amylase variation. A comparison with amylase patterns of Asellus meridianus Racovitza, which often occurs sympatrically with $A$. aquaticus, is also made.

\section{METHODS}

\section{Breeding experiments}

Animals were collected from a pond and from the River Foss near York in March 1984. Initial matings were made by isolating males and females found in precopula in the wild (Foss) or by pairing a male with a non-gravid female (one individual from the pond, the other from the Foss). Pairs 
were maintained in small plastic tubs $2.5 \mathrm{~cm}$ deep by $5 \mathrm{~cm}$ diameter, containing filtered pond water and a decaying elm leaf. Males were homogenised when the female became gravid and females homogenised when all young had escaped from the brood pouch. Progeny were moved to plastic boxes $17 \mathrm{~cm}$ by $11.5 \mathrm{~cm}$ by $5 \mathrm{~cm}$ deep containing about $1 \mathrm{~cm}$ depth of filtered pond water and decaying elm leaves. All animals were maintained at $19^{\circ} \mathrm{C}$ under an 18 hour: 6 hour, light:dark cycle. Later matings were made between progeny of the initial crosses after they had been scored for amylase phenotype using faecal extracts (see below).

\section{Electrophoresis}

Horizontal polyacrylamide gels ( 7.5 per cent acrylamide monomer) $19 \mathrm{~cm} \times 10.5 \mathrm{~cm} \times 1.5 \mathrm{~mm}$ deep were made and run with the tris/citric acid buffer, pH 7.0, of Den Boer (1978). Extracts were prepared by homogenising animals in $50 \mu$ l of reservoir buffer (as in Den Boer, 1978, but diluted $\times 2$ ) in a drilled perspex block using a rotating glass rod. These were taken up in $1 \times 6 \mathrm{~mm}$ filter paper wicks and inserted into a slit cut along the length of the gel, about $2.0 \mathrm{~cm}$ from the cathodal end. The gel was covered with plastic film and connected to the reservoirs with four layers of J-cloth. An ice pack was placed on top and the gel run at $4^{\circ} \mathrm{C}$ at a constant voltage of $250 \mathrm{~V}$ for $2 \frac{1}{2}$ hours.

Gels were incubated for $45 \mathrm{~m}$ in a citric acid/trisodium citrate buffer containing $0 \cdot 1 \mathrm{M} \mathrm{NaCl}$ and 2 per cent $\mathrm{W} / \mathrm{V}$ hydrolysed starch (final $\mathrm{pH} 5 \cdot 6$ ), in a shaking water bath at $36^{\circ} \mathrm{C}$. After a brief rinse in water they were immersed in an iodine/potassium iodide solution until clear amylase bands appeared. Gels were routinely recorded by contact printing.

\section{Faecal analysis}

During the course of this work it was found that animals could be scored for amylase phenotype using faecal extracts. Individuals were blotted, placed in stoppered glass tubes $(4 \mathrm{~cm} \times 1 \mathrm{~cm}$ diameter) containing $20-50 \mu \mathrm{l}$ of filtered pond water and left overnight at $19^{\circ} \mathrm{C}$. The following day animals were removed and the water soaked up into wicks and electrophoresed.

\section{RESULTS}

Fig. 1 is a composite diagram of a gel showing all the commonly observed zones. Amylases seem to

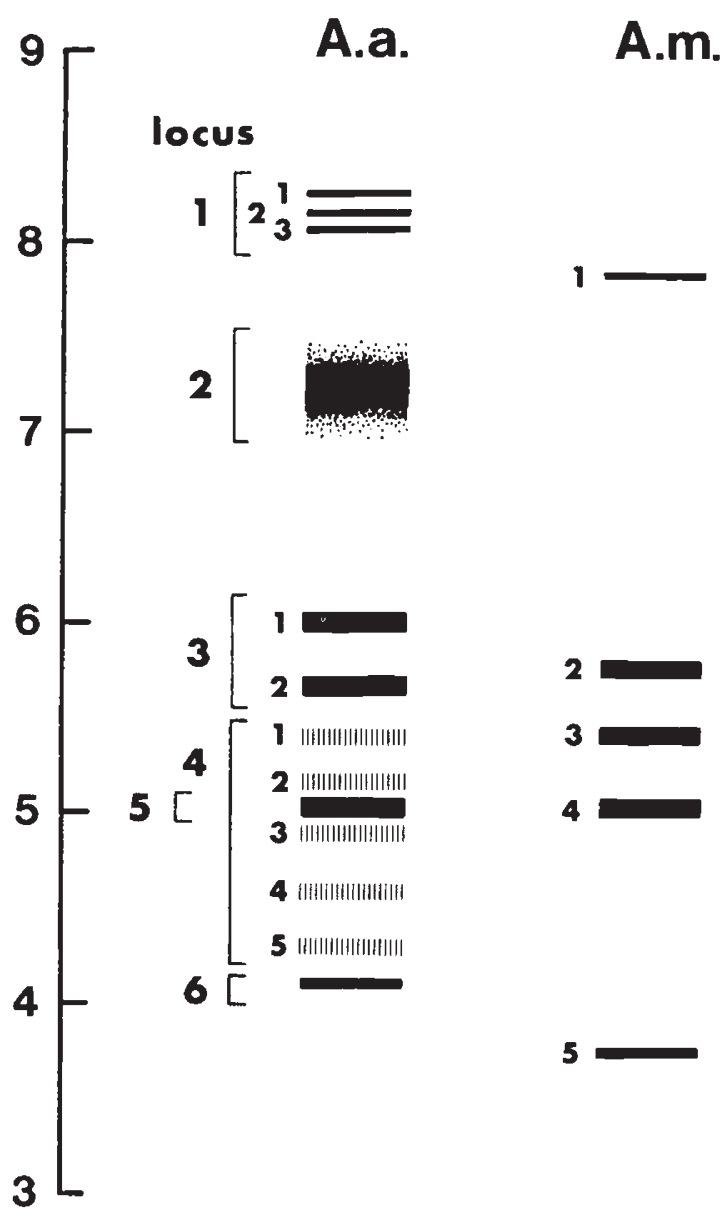

Figure 1 Composite diagram showing the common amylase zones found in Asellus aquaticus (A.a.) and A. meridianus (A.m.). Scale gives distance (cms) from the origin; the anode is at the top. Hatched zones (Amy 4) do not appear when gels are incubated at $\mathrm{pH} \mathbf{4} \cdot 2$.

be produced by six loci, as indicated in the figure. Within a locus allelic zones are numbered from anode to cathode. Breeding data are available only for loci Amy 3, Amy 4 and Amy 5. Other zones have been assigned to loci on the basis of their position and appearance, either because no variation was detected (Amy 6$)$ or because variation could not be reliably scored (Amy 1 and $A m y 2$ ).

Amy 3 (table 1), with two active alleles, $A m y 3^{1}$ and $A m y 3^{2}$, and a null, $A m y 3^{-}$, is almost certainly the same locus as was described by Lomholt and Christensen (1970) (see below).

Amy 4 (table 2) has at least six alleles, five producing active zones, $A m y 4^{1}$ through to $A m y 4^{5}$, and a null, $A m y 4^{-}$. All but $A m y 4^{4}$ are represented in the table. Zone 4 has been assigned to this locus 
Table 1 Segregation of zones at $A m y 3$

\begin{tabular}{|c|c|c|c|c|c|c|c|c|}
\hline Parents & $\begin{array}{l}\text { No. } \\
\text { broods }\end{array}$ & 1 & $1 / 2$ & $\begin{array}{c}\text { Progeny } \\
2\end{array}$ & $-1-$ & Total & $\begin{array}{l}\mathrm{P}^{\mathrm{a}} \\
\text { (total) }\end{array}$ & $\begin{array}{l}\mathrm{P}^{\mathrm{b}} \\
\text { (hetero.) }\end{array}$ \\
\hline $1 / 1 \times 1$ & 12 & 409 & - & - & - & 409 & - & - \\
\hline $1 / 2 \times 1 / 2$ & 5 & 56 & 104 & 45 & - & 205 & NS & NS \\
\hline $1 / 1 \times 2 / 2$ & 1 & - & 24 & - & - & 24 & - & - \\
\hline $1 / 1 \times 2 /-$ & 6 & 73 & 107 & - & - & 180 & $<0.02$ & NS \\
\hline
\end{tabular}

${ }^{\text {a }}$ Probability associated with a $\chi^{2}$ test on total numbers, based on a N.H. of simple Mendelian ratios

${ }^{b}$ Probability associated with a $\chi^{2}$ test based on a N.H. of no heterogeneity in genotype/phenotype proportions between broods Parents designated by phenotype (e.g. 1) could be homozygous for the active allele or heterozygous for the active allele and a null allele

because, in common with other active Amy 4 zones, it fails to stain when the gel is incubated at pH $4 \cdot 2$ rather than at $\mathrm{pH} 5 \cdot 6$. In addition to these six alleles there are hints of further variation at this locus. In four broods a lightly staining zone 3 segregated with normal, heavily staining zones. In another brood a lightly staining zone 2 segregated (table 2). These fainter bands are not a result of heterozygosity with the null allele and may indicate additional alleles with activity rather than mobility differences, or result from the presence of variation at a cis-acting regulatory locus affecting Amy 4. A parent of one brood (table 2) had a single Amy 4 zone (2a) migrating slightly faster than the normal zone 2 . Segregation in the offspring suggests that the parent was homozygous for this rare mobility variant; other Amy 4 zones in the offspring migrated normally.

Table 2 Segregation of zones at Amy 4

\begin{tabular}{|c|c|c|c|c|c|c|c|c|c|c|c|c|c|c|}
\hline Parents & $\begin{array}{l}\text { No. } \\
\text { broods }\end{array}$ & 1 & $1 / 2$ & 2 & $2 / 3$ & 3 & $\begin{array}{l}\text { ny } \\
1 / 3\end{array}$ & 5 & $2 / 5$ & $3 / 5$ & $-1-$ & Total & $\begin{array}{l}\mathrm{P}^{\mathrm{a}} \\
\text { (total) }\end{array}$ & $\begin{array}{l}\mathrm{P}^{\mathrm{b}} \\
\text { (hetero.) }\end{array}$ \\
\hline $1 / 2 \times 3 / 3$ & 1 & - & - & - & 18 & - & 22 & - & - & - & - & 40 & NS & - \\
\hline $1 / 3 \times 2 / 3$ & 1 & - & 5 & - & 9 & 17 & 8 & - & - & - & - & 39 & $<0.05$ & - \\
\hline $1 / 3 \times 2 /-$ & 2 & 11 & 11 & - & 10 & 19 & - & - & - & - & - & 51 & NS & NS \\
\hline $2 a / 2 a^{c} \times 2 / 3$ & 1 & - & - & 13 & 16 & - & - & - & - & - & - & 29 & NS & - \\
\hline $2 / 2 \times 2 / 3$ & 5 & - & - & 86 & 85 & - & - & - & - & - & - & 171 & NS & NS \\
\hline $2 / 2 \times-1-$ & 2 & - & - & 41 & - & - & - & - & - & - & - & 41 & - & - \\
\hline $2 / 2 \times 3 /-$ & 1 & - & 一 & 55 & 32 & - & - & - & - & - & - & 87 & $<0.02$ & - \\
\hline $2 / 2 \times 3^{c} /-$ & 1 & - & - & 24 & $24^{e}$ & - & - & - & - & - & - & 48 & NS & - \\
\hline $2 /-\times 3 / 3$ & 1 & - & - & - & 7 & 7 & - & - & - & - & - & 14 & NS & - \\
\hline $2 /-\times 3 /-$ & 2 & - & - & 35 & 23 & 20 & - & - & - & - & 19 & 97 & NS & NS \\
\hline $2 / 3 \times 3 /-$ & 3 & - & - & 44 & 49 & 55 & - & - & - & - & - & 148 & $<0.01$ & NS \\
\hline $2 / 5 \times 3^{c} /-$ & 1 & - & - & 19 & $22^{e}$ & - & - & 13 & - & $15^{e}$ & - & 69 & NS & - \\
\hline $3 / 3 \times 3$ & 4 & - & - & - & - & 128 & - & - & - & - & - & 128 & - & - \\
\hline $3 \times 3$ & 1 & - & - & - & - & $3521^{e}$ & - & - & - & - & - & 56 & NS & - \\
\hline $3 /-\times 3 /-$ & 1 & - & - & - & - & 44 & - & - & - & - & 21 & 65 & NS & - \\
\hline $3 / 3 \times-1-$ & 1 & - & - & - & - & 26 & - & - & - & - & - & 26 & - & - \\
\hline $3 /-x-1-$ & 1 & - & - & - & - & 38 & - & - & - & - & 24 & 62 & NS & - \\
\hline
\end{tabular}

${ }^{a, b}$ See legend to table 1

${ }^{c}$ Zone migrating to a position between zones 1 and 2 . In the progeny it segregated as $2 \mathrm{a} / 2$ and $2 \mathrm{a} / 3$ shown under the 2 and $2 / 3$ columns, respectively

${ }^{d}$ Parent of one brood subsequently shown by progeny testing to be $2 /-$

Faintly staining zones-as indicated in parent

'Contaminant (?) 
Variation at Amy 5 (table 3) consists of the presence or absence of an active zone, apparently controlled by two alleles, Amy $5^{1}$ and a null, Amy $5^{-}$. The active zone migrates to an area of the gel occupied by $A m y 4$ products but can be easily distinguished from them by its persistent activity at $\mathrm{pH} 4 \cdot 2$. The Amy 5 zone is not produced by an allele at $A m y 3$ since one individual has been found which was heterozygous at the latter locus and also possessed an active Amy 5 zone.

Locus Amy 1 codes for at least three electrophoretically distinct products which stain weakly, if at all. Differences in mobility between the zones are small. Amy 2 produces a very diffuse zone which can occasionally be scored as fast or slow; in juveniles it is usually absent altogether. Unlike all other amylases Amy 2 zones appear whitish, rather than clear, against the blue background. Finally, Amy 6 is responsible for a weakly staining zone which is invariant in all animals examined.

Many broods provide information on linkage between Amy 3, Amy 4 and Amy 5 (table 4). All three are closely linked with only two recombinants, between $A m y 3$ and $A m y$, recognised in 961 offspring, giving a recombination frequency of $0 \cdot 2 \pm 0 \cdot 3$ per cent $( \pm 95$ per cent confidence interval). Linkage relationships of these three with the other loci are unknown.

Some of the later matings were established with animals previously typed from faecal extracts. In all cases in which many faecal pellets were produced and strong amylase bands obtained, patterns of variation were identical to those found subsequently when whole animals were homogenised. Evidently contamination from bacterial sources is not a problem and the method commends itself not only for breeding studies but also for the nondestructive sampling of small populations.

In contrast to the high level of variation found in most populations of Asellus aquaticus, $A$. meridianus appears to be monomorphic (fig. 1), and so zones cannot be assigned to particular loci. A locus homologous to Amy 4 seems to be absent however, as all $A$. meridianus amylases are active at $\mathrm{pH} 4 \cdot 2$. A. meridianus also has no trace of a whitish-staining, diffuse zone which might be homologous with Amy 2.

\section{DISCUSSION}

Amylases in Asellus aquaticus seem to be produced by six loci with segregation ratios at the three studied in detail showing no association with sex. The pattern of simple, co-dominant inheritance of electrophoretically distinct products at $A m y 3$ and Amy 4 (and Amy 1?) suggest monomeric enzymes, in agreement with the universal finding for amylases in other animals (Karn and Malacinski, 1978).

Previous work on A. aquaticus by Christensen and colleagues (Lomholt and Christensen, 1970; Christensen et al., 1974; Christensen, 1977) and Robson $(1973 ; 1979)$ assumed a single amylase locus. This is almost certainly identical to $A m y$, as defined here, for two reasons. First, the most active amylase zones are produced by $A m y$, Amy 4 and $A m y$ 5. The active product of $A m y 5$ is usually absent in most British populations, and possibly also in Denmark, and, at the incubation pH used by the Danish workers ( $\mathrm{pH} 4 \cdot 6$ ), activity in the Amy 4 region is very weak. Highly active zones would therefore result from Amy 3 alone. (Lomholt and Christensen (1970) and Robson, (1973) do mention shadow bands, cathodal to their $A_{1} / A_{2}$ system, which were probably products of Amy 4). Second, Robson (1973) compared amylase patterns from $A$. aquaticus and $A$. meridianus and showed that the latter had two active zones cathodal to the $A_{1} / A_{2}$ system of the former. The two most active zones in $A$. meridianus are 3 and 4, cathodal to the products of Amy 3 (fig. 1).

The presence of a null allele at Amy 3 may account for the observation of some individuals lacking both $A_{1}$ and $A_{2}$ zones (Christensen, personal communication) and explain the deficit of heterozygotes in many natural populations (Christensen et al., 1974). At all three amylase loci studied in detail, null alleles are present. In particular, the null at Amy 5 is by far the commonest allele (table 5) and is fixed in the majority of populations around York (Oxford, unpublished

Table 3 Segregation of zones at Amy 5

\begin{tabular}{lccrrrr}
\hline Parents & $\begin{array}{l}\text { No. } \\
\text { broods }\end{array}$ & $1 /-$ & $-/-$ & Total & $\begin{array}{l}\mathbf{P}^{\mathrm{a}} \\
\text { (total) }\end{array}$ & $\begin{array}{l}\mathrm{P}^{\mathrm{b}} \\
\text { (hetero.) }\end{array}$ \\
\hline$-/-\times-/-$ & 37 & - & 1393 & 1393 & - & - \\
$1 /-\times-/-$ & 7 & 155 & 157 & 312 & NS & NS \\
\hline
\end{tabular}

${ }^{\mathrm{a}, \mathrm{b}}$ See legend to table 1 
Table 4 Numbers of individuals in which recombination would have been detectable

\begin{tabular}{lrcr}
\hline & \multicolumn{3}{c}{ Locus pair } \\
Chromosome type & $3-4$ & $3-5$ & $4-5$ \\
\hline $\begin{array}{l}\text { Non-recombinant } \\
\text { Recombinant }\end{array}$ & 959 & 148 & 224 \\
Total & 2 & 0 & 0 \\
\hline
\end{tabular}

$\%$ recombination $(3-4)=0 \cdot 2 \pm 0 \cdot 3$

Table 5 Estimated frequency of alleles at three loci in breeding material from the Foss

\begin{tabular}{llll}
\hline Allele & Amy 3 & $\begin{array}{c}\text { Locus } \\
\text { Amy 4 }\end{array}$ & Amy 5 \\
\hline- & 0.027 & 0.179 & 0.954 \\
1 & 0.767 & 0.018 & 0.046 \\
2 & 0.205 & 0.303 & - \\
$2 \mathrm{a}^{\mathrm{g}}$ & - & 0.018 & - \\
3 & - & 0.429 & - \\
$(3)^{\mathrm{h}}$ & - & 0.045 & - \\
5 & - & 0.009 & - \\
\hline
\end{tabular}

Frequencies are estimated from parental genotypes as deduced from their offspring. Parents apparently homozygous for the same active allele are scored as homozygotes; some null alleles may therefore have been missed. Only animals taken directly from the Foss are included; 56 animals were scored ${ }^{\mathrm{g}}$ Zone migrates to a position between zones 1 and 2

${ }^{\mathrm{h}}$ Faintly staining zone

data). The persistence of null alleles at loci coding for digestive enzymes is surprising. However, amylases are revealed on gels by virtue of their ability to cleave the amylose present in starch. They may also attack other substrates $e . g$., glycogen and amylopectin, and until further biochemical studies have been made it would be premature to regard products of null alleles as enzymatically inactive.

Loci Amy 3, Amy 4 and Amy 5 are closely linked (table 4). Multiple amylase loci are common in other invertebrates and also in vertebrates, and are often linked (reviewed by Karn and Malacinski, 1978). This situation could arise by tandem duplication of existing loci. In A. aquaticus products of one of the linked loci, Amy 4, differ markedly in their properties from those of the other two loci. For example, they are inactive at $\mathrm{pH} 4 \cdot 2$ whereas products of Amy 3 and Amy 5 retain high activity. Also, when crude extracts are incubated for extended periods at $19^{\circ} \mathrm{C}, A m y 4$ (represented by zone 2) loses activity after seven days but Amy 3 (represented by zone 1) is still highly active at 22 days. Identical results are found with both non- sterile and filter-sterilised extracts. Products of other alleles at these loci have yet to be tested. Thus, if multiple loci and linkage are a result of tandem duplication, there is evidence in Asellus for divergent evolution since the initial duplication event.

Tight linkage between Amy 3 and two other amylase loci may mean that the simple habitat selection model of Christensen (1977) will have to be reinterpreted. The three amylase loci will act as a supergene and interactions between the loci could be important in determining adaptive behaviour of individuals. Breeding work is now in progress to isolate lines having different combinations of alleles at the supergene loci. Only then will it be possible to investigate habitat selection induced by alleles at each of the loci in turn.

It was noted above that homologies between $A$. aquaticus and $A$. meridianus amylase loci are not easy to determine. Amy 2 and Amy 4 are apparently absent as judged by appearance on the gel and by activity at $\mathrm{pH} 4 \cdot 2$. In electrophoretic mobility and staining intensities, $A$. meridianus zones 1 and 5 might tentatively be suggested as homologues of $A m y 1$ and $A m y 6$ respectively. It is not altogether surprising that amylase patterns do not correspond well in these species; they have different chromosome numbers ( $A$. aquaticus, $2 n=$ $16, A$. meridianus, $2 \mathrm{n}=10$ ) and, on morphological grounds, $A$. meridianus is often assigned to a different sub-genus, Proasellus (see Williams, 1962). The ecological significance of amylase polymorphism vs. monomorphism in species living sympatrically has yet to be assessed.

Acknowledgements I am most grateful to Dr Bent Christensen for allowing me access to his unpublished data.

\section{REFERENCES}

CHRISTENSEN, B. 1977. Habitat preference among amylase genotypes in Asellus aquaticus (Isopoda, Crustacea). Hereditas, 87, 21-26.

CHRISTENSEN, B., LOMHOLT, B. AND JELNES, J. 1974. Selection and mechanical mixing operating on a 2-allele amylase system in Asellus aquaticus (Isopoda, Crustacea). Hereditas, 77, 255-262.

DEN BOER, M. H. 1978. Isoenzymes and migration in the African armyworm Spodoptera exempta (Lepidoptera, Noctuidae). J. Zool. Lond. 185, 539-553.

KARN, R. C. AND MALACINSKI, G. M. 1978. The comparative biochemistry, physiology and genetics of animal amylases. Adv. Comp. Physiol. Biochem., 7, 1-103.

LOMHOLT, B. AND CHRISTENSEN, B. 1970. Amylase polymorphism in the waterbug, Asellus aquaticus, revealed by cellulose acetate electrophoresis. Hereditas, 64, 177-180. 
ROBSON, C. M. 1973. Ecological investigations on the amylase polymorphism in Asellus aquaticus (L.). Unpublished dissertation. University of Copenhagen.

RobSON, C. M. 1979. Purification and properties of digestive amylase of Asellus aquaticus (L.) (Crustacea, Isopoda). Comp. Biochem. Physiol., 62B, 501-505.
ROSSI, L. AND VITAGLIANO-TADINI, G. 1978. Role of adult faeces in the nutrition of larvae of Asellus aquaticus (Isopoda). Oikos, 30, 109-113.

WILLIAMS, w. D. 1962. Some remarks on phenotypic variation and genetic isolation in Asellus (Isopoda, Asellota). Crustaceana, 3, 279-284. 